\title{
Simulation of the Flow over NREL's S834 Airfoil at two different Reynolds numbers
}

\author{
Spyridon D. Skaltsogiannis, Eleni C. Douvi, Dimitra C. Douvi, Dionissios P. Margaris
}

\begin{abstract}
The current study examines the steady-state two-dimensional subsonic flow over NREL's S834 airfoil at various angles of attack using a commercial Computational Fluid Dynamics (CFD) code. The simulations were performed for various angles of attack and at two different Reynolds numbers, $\operatorname{Re}=3.5 \times 10^{5}$ and $\operatorname{Re}=5 \times 10^{5}$. The Spalart-Allmaras, the Realizable $k-\varepsilon$ and the Standard k- $\omega$ turbulence models were tested to find which is the most suitable to accurately predict the aerodynamic coefficients of the airfoil. Additionally, in order to validate the numerical results a comparison against reliable experimental data was also conducted. Calculations have shown that at low angles of attack the relative error of the computational results was negligible, although for high angles of attack this error is significantly high.
\end{abstract}

Index Terms - Aerodynamic performance, Computational Fluid Dynamics, S834 airfoil, Turbulence models.

\section{INTRODUCTION}

Renewable energy technologies are the energy solution for the future since the results of climate change are more intense year by year. Among the renewable energy sources (RES), wind energy is one of the most popular since its cost is low, and it has minimum environmental effects.

The performance of the Horizontal Axis Wind Turbines (HAWTs) depends on the aerodynamic performance of the airfoils from which their blades are constructed. Recently, researchers have shown an increased interest in studying numerically the airfoils aerodynamics, by the help of commercial Computational Fluid Dynamics (CFD) codes. Almost 10 years ago, in 2012, Douvi et al. [1] simulated the aerodynamic behavior of NACA 0012 airfoil at Reynolds number of $3 \times 10^{6}$, with three turbulence models, available in the CFD code ANSYS Fluent. They found out that the CFD code was not able to simulate the transition point and the predicted drag coefficient values were higher than the corresponding experimental data. In the same year, Wang and Liu [2] studied numerically DU-93-W-210 and S809 airfoils, with ANSYS Fluent and they also concluded that the obtained results for the drag coefficient were inconsistent with the experimental data.

Ibrahim et al. [3] studied both numerically and experimentally a wind turbine airfoil at two different

Spyridon D. Skaltsogiannis, Mechanical Engineering and Aeronautics Department, University of Patras, Patras, Greece

Eleni C. Douvi, Mechanical Engineering and Aeronautics Department, University of Patras, Patras, Greece

Dimitra C. Douvi, Mechanical Engineering and Aeronautics Department, University of Patras, Patras, Greece

Dionissios P. Margaris, Mechanical Engineering and Aeronautics Department, University of Patras, Patras, Greece
Reynolds numbers, $2.5 \times 10^{4}$ and $5 \times 10^{4}$, and they found that three-dimensional effects were not captured by two-dimensional simulations. In 2014, Shah et al. [4] designed and studied numerically a novel airfoil for small HAWT, operating at various Reynolds numbers, from $6 \times 10^{4}$ up to $5 \times 10^{5}$. A year later, the same researchers [5] analyzed computationally the transition from laminar to turbulent region and the laminar separation bubble over UBD5494 airfoil at five different Reynolds numbers. From their results it was obvious that the size of separation bubble decreases when Reynolds number increases. In 2016, Chaudhary and Nayak [6] studied the correlation between angle of attack and Reynolds number for NACA 63-412 and NACA 63-415 airfoils, and by comparing the lift-to-drag ratio for the two examined airfoils, they concluded that NACA 63-415 airfoil performs better.

In 2017, Mauro et al. [7] coupled ANSYS Fluent with a Micro-Genetic Algorithm, in order to get more accurate results. They demonstrated that the most accurate turbulence model was the Transitional SST model and they calibrated its local correlation parameters, using the well-known S809 airfoil lift coefficient data. Then, they utilized the same correlation parameters for NACA 0018 airfoil and the obtained results were acceptable. The ultimate purpose of their study was to use this calibration in order to improve the HAWT rotor simulations.

In 2019, Belfkira et al. [8] studied by the help of ANSYS Fluent and XFOIL the NACA63-618 airfoil, which is used in HAWT blades, at various angles of attack and operating at a Reynolds number of $3 \times 10^{6}$. They validated the obtained results by comparing them with corresponding experimental data and concluded that the Spalart-Allmaras turbulence model was the most appropriate to calculate the aerodynamic coefficients for this airfoil.

Recently, Khan et al. [9] studied the flow over NACA 0018 airfoil at positive angles of attack, ranging from 0 up to 18 degrees for various Reynolds numbers with four different turbulence models in ANSYS Fluent. They concluded that the SST k- $\omega$ turbulence model predicted more accurately the lift coefficient for low angles of attack, whilst the Transition k-kl- $\omega$ model was able to capture the flow separation and reattachment regions.

In this paper, the flow over S834 airfoil is studied, by the help of the commercial CFD code, ANSYS Fluent [10]. The aerodynamic behavior of this airfoil was examined at various angles of attack, ranging approximately from -6 degrees to 13 degrees and at two Reynolds numbers, specifically $\mathrm{Re}=3.5 \times 10^{5}$ and $\mathrm{Re}=5 \times 10^{5}$. 


\section{COMPUTATIONAL METHOD}

NREL's S834 is a low Reynolds airfoil and belongs to the National Renewable Energy Laboratory family of airfoils [11]. It is typically used for small HAWTs blade designs, with a rotor diameter equal from $1 \mathrm{~m}$ to $3 \mathrm{~m} \mathrm{[12].}$ S834 airfoil maximum thickness is $15 \%$ at $39.5 \%$ of the chord length and maximum camber is $1.6 \%$ at $60 \%$ of the chord length [13]. Fig. 1 illustrates S834 airfoil profile [14].

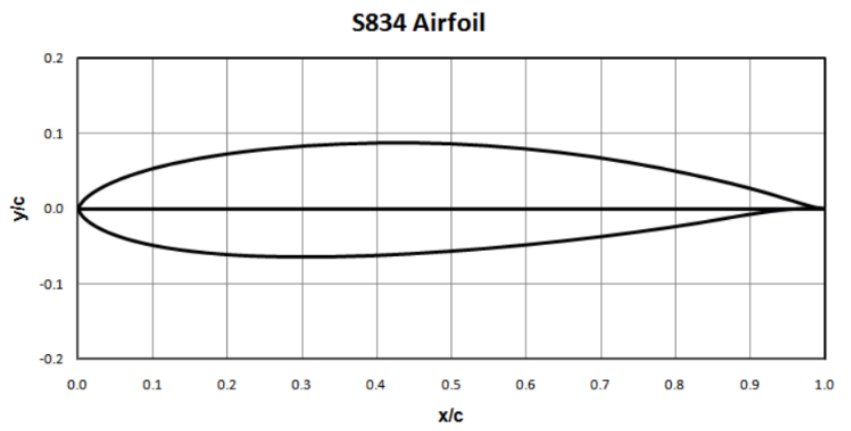

Fig. 1. NREL's S834 airfoil profile [14].

For the purposes of the present study, the chord of the airfoil is $1 \mathrm{~m}$. Additionally, the flow domain consists of a semicircle and a rectangle. The center of the semicircle coincides with the trailing edge of the airfoil, where the rectangle also starts. The semicircle has a radius of $12 \mathrm{~m}$ and the rectangle is $21 \mathrm{~m}$ in length, while its width is $24 \mathrm{~m}$.

The C-type flow domain is fully structured and consists of 80,000 quadrilateral cells, as presented in Fig. 2. The grid becomes denser around the airfoil and the trailing edge as shown in Fig. 3.

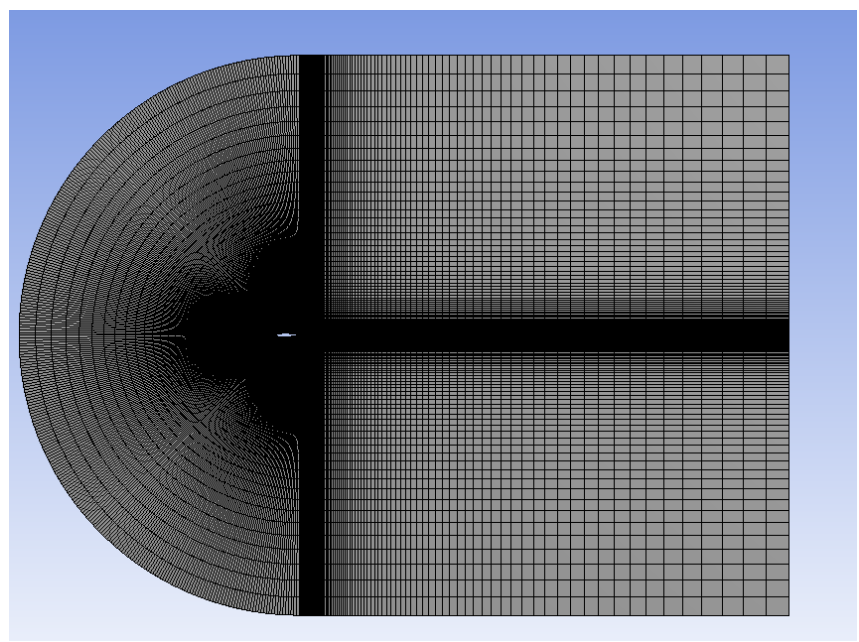

Fig. 2. 80,000 cells structured mesh

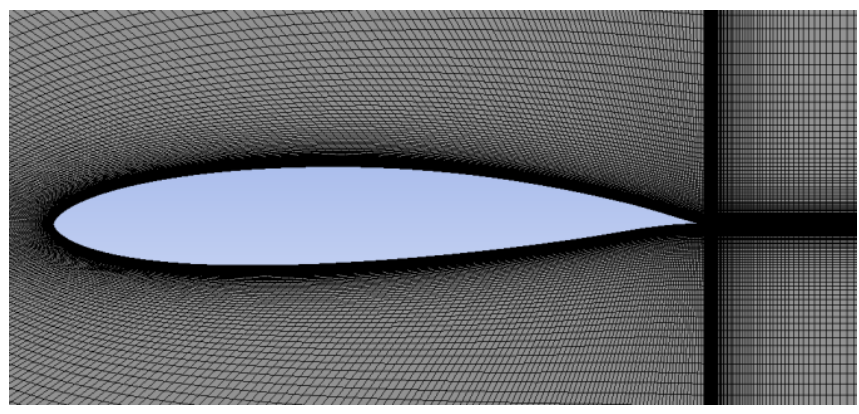

Fig. 3. Structured mesh around airfoil
The 80,000 number of cells were chosen after a grid independence study. The study demonstrates that the error in the results is small when the number of cells is between 80,000 cells and another number that is greater than 80,000 cells (e.g. 120,000, 150,000). Moreover, as the number of cells increases, so do the time and the computational power required to calculate the results. Additionally, the $\mathrm{y}^{+}$value is smaller than 3 and the viscous boundary sublayer can be solved accurately. The semicircle and the upper and lower sides of the rectangle are set as velocity inlet, the right side of the rectangle is set as outlet and the airfoil as wall.

The ANSYS Fluent code solves the RANS equations using finite volume discretization. In this analysis, air temperature is equal to $300 \mathrm{~K}$, atmospheric pressure is $1 \mathrm{~atm}$, viscosity $\mu$ for the given conditions is equal to $1.7894 \times 10^{-5} \mathrm{~kg} / \mathrm{ms}$ and air density $\rho$ is equal to $1.225 \mathrm{~kg} / \mathrm{m}^{2}$.

Furthermore, free stream velocity depends on the Reynolds number. The relation between Reynolds number and free stream velocity is demonstrated in the following equation:

$$
R e=\frac{\rho u_{\infty} c}{\mu}
$$

In (1), $u_{\infty}$ is the free stream velocity and $c$ is the chord length of the airfoil. The chord length is equal to $1 \mathrm{~m}$ and the values $\rho$ and $\mu$ are as mentioned above, so the free stream velocity is equal to $5.113 \mathrm{~m} / \mathrm{s}$ and $7.304 \mathrm{~m} / \mathrm{s}$ for Reynolds numbers of $3.5 \times 10^{5}$ and $5 \times 10^{5}$, respectively.

According to Mach number, the flow is incompressible. Mach number $\mathrm{M}$ is defined as follows:

$$
\mathrm{M}=\frac{u_{\infty}}{\alpha_{\infty}}
$$

In (2), $\alpha_{\infty}$ is the sound velocity and $u_{\infty}$ the free stream velocity. For these conditions, sound velocity is equal to $347.5 \mathrm{~m} / \mathrm{s}$, which leads to Mach number values lower than the critical Mach number $\mathrm{M}_{\mathrm{cr}}=0.15$, which determines whether the flow is compressible or not.

In this study the Realizable k- $\varepsilon$, the Spalart-Allmaras and the Standard k- $\omega$ turbulence models are examined. The numerical results obtained in the present study were compared with valid wind tunnel experimental data by Selig and McGranahan [15]. For $\mathrm{Re}=3.5 \times 10^{5}$ the angle of attack ranges from $-6.08^{\circ}$ to $13.31^{\circ}$, while for $\mathrm{Re}=5 \times 10^{5}$ the angle of attack ranges from $-6.06^{\circ}$ to $13.24^{\circ}$.

\section{RESULTS AND DISCUSSION}

\section{A. Aerodynamic Coefficients}

The aerodynamic coefficients were calculated using three different turbulence models, as described above. In order to validate the results, they were compared with corresponding reliable experimental data by Selig and McGranahan [15]. From Table I to Table IV the experimental data are compared with the computational results. From Fig. 4 to Fig. 7 are presented the lift and drag coefficients versus angle of attack for S834 airfoil. 
Table I. Lift coefficient values from Selig and McGranahan [15] and computational results from three turbulence models at $\mathrm{Re}=3.5 \times 10^{5}$

\begin{tabular}{|c|c|c|c|c|}
\hline $\begin{array}{c}\text { angle of } \\
\text { attack }\end{array}$ & $\begin{array}{c}\text { Selig and } \\
\text { McGranahan }\end{array}$ & $\begin{array}{c}\text { Spalart- } \\
\text { Allmaras }\end{array}$ & $\begin{array}{c}\text { Realizable } \\
\boldsymbol{k}-\boldsymbol{\varepsilon}\end{array}$ & $\begin{array}{c}\text { Standard } \\
\boldsymbol{k}-\boldsymbol{\omega}\end{array}$ \\
\hline $\mathbf{- 6 . 0 8}$ & -0.423 & -0.409 & -0.410 & -0.419 \\
\hline $\mathbf{- 4 . 0 4}$ & -0.189 & -0.209 & -0.203 & -0.217 \\
\hline $\mathbf{- 2 . 0 0}$ & 0.024 & 0.000 & 0.011 & -0.008 \\
\hline $\mathbf{0 . 0 8}$ & 0.238 & 0.215 & 0.230 & 0.212 \\
\hline $\mathbf{2 . 1 1}$ & 0.441 & 0.425 & 0.441 & 0.424 \\
\hline $\mathbf{4 . 2 2}$ & 0.624 & 0.634 & 0.653 & 0.637 \\
\hline $\mathbf{6 . 1 8}$ & 0.806 & 0.816 & 0.837 & 0.827 \\
\hline $\mathbf{8 . 2 7}$ & 0.926 & 0.992 & 1.012 & 1.015 \\
\hline $\mathbf{1 0 . 2 5}$ & 1.037 & 1.134 & 1.152 & 1.069 \\
\hline $\mathbf{1 2 . 3 2}$ & 1.081 & 1.239 & 1.263 & 1.184 \\
\hline $\mathbf{1 3 . 3 1}$ & 1.076 & 1.269 & 1.299 & 1.016 \\
\hline
\end{tabular}

Table II. Drag coefficient values from Selig and McGranahan [15] and computational results from three turbulence models at $\mathrm{Re}=3.5 \times 10^{5}$

\begin{tabular}{|c|c|c|c|c|}
\hline $\begin{array}{c}\text { angle of } \\
\text { attack }\end{array}$ & $\begin{array}{c}\text { Selig and } \\
\text { McGranahan }\end{array}$ & $\begin{array}{c}\text { Spalart- } \\
\text { Allmaras }\end{array}$ & $\begin{array}{c}\text { Realizable } \\
\boldsymbol{k}-\boldsymbol{\varepsilon}\end{array}$ & $\begin{array}{c}\text { Standard } \\
\boldsymbol{k}-\boldsymbol{\omega}\end{array}$ \\
\hline $\mathbf{- 6 . 0 8}$ & 0.015 & 0.020 & 0.019 & 0.021 \\
\hline $\mathbf{- 4 . 0 4}$ & 0.013 & 0.018 & 0.018 & 0.018 \\
\hline $\mathbf{- 2 . 0 0}$ & 0.011 & 0.017 & 0.017 & 0.017 \\
\hline $\mathbf{0 . 0 8}$ & 0.010 & 0.017 & 0.017 & 0.016 \\
\hline $\mathbf{2 . 1 1}$ & 0.010 & 0.018 & 0.018 & 0.017 \\
\hline $\mathbf{4 . 2 2}$ & 0.010 & 0.020 & 0.019 & 0.018 \\
\hline $\mathbf{6 . 1 8}$ & 0.011 & 0.023 & 0.022 & 0.021 \\
\hline $\mathbf{8 . 2 7}$ & 0.016 & 0.028 & 0.026 & 0.025 \\
\hline $\mathbf{1 0 . 2 5}$ & 0.026 & 0.035 & 0.032 & 0.029 \\
\hline $\mathbf{1 2 . 3 2}$ & 0.049 & 0.046 & 0.041 & 0.030 \\
\hline $\mathbf{1 3 . 3 1}$ & 0.072 & 0.054 & 0.047 & 0.024 \\
\hline
\end{tabular}

Table III. Lift coefficient values from Selig and McGranahan [15] and computational results from three turbulence models at $\mathrm{Re}=5 \times 10^{5}$

\begin{tabular}{|c|c|c|c|c|}
\hline $\begin{array}{c}\text { angle of } \\
\text { attack }\end{array}$ & $\begin{array}{c}\text { Selig and } \\
\text { McGranahan }\end{array}$ & $\begin{array}{c}\text { Spalart- } \\
\text { Allmaras }\end{array}$ & $\begin{array}{c}\text { Realizable } \\
\boldsymbol{k}-\boldsymbol{\varepsilon}\end{array}$ & $\begin{array}{c}\text { Standard } \\
\boldsymbol{k}-\boldsymbol{\omega}\end{array}$ \\
\hline $\mathbf{- 6 . 0 6}$ & -0.374 & -0.407 & -0.413 & -0.425 \\
\hline $\mathbf{- 4 . 0 0}$ & -0.173 & -0.201 & -0.202 & -0.212 \\
\hline $\mathbf{- 1 . 9 6}$ & 0.039 & 0.010 & 0.012 & 0.004 \\
\hline $\mathbf{0 . 0 7}$ & 0.246 & 0.222 & 0.226 & 0.220 \\
\hline $\mathbf{2 . 1 4}$ & 0.461 & 0.436 & 0.442 & 0.438 \\
\hline $\mathbf{4 . 1 7}$ & 0.662 & 0.639 & 0.647 & 0.646 \\
\hline $\mathbf{6 . 1 9}$ & 0.808 & 0.830 & 0.839 & 0.844 \\
\hline $\mathbf{8 . 2 6}$ & 0.937 & 1.005 & 1.017 & 1.033 \\
\hline $\mathbf{1 0 . 2 4}$ & 1.056 & 1.148 & 1.163 & 1.198 \\
\hline $\mathbf{1 2 . 3 6}$ & 1.119 & 1.256 & 1.283 & 1.348 \\
\hline $\mathbf{1 3 . 2 4}$ & 1.119 & 1.282 & 1.317 & 1.401 \\
\hline
\end{tabular}

Table IV. Drag coefficient values from Selig and McGranahan [15] and computational results from three turbulence models at $\mathrm{Re}=5 \times 10^{5}$

\begin{tabular}{|c|c|c|c|c|}
\hline $\begin{array}{c}\text { angle of } \\
\text { attack }\end{array}$ & $\begin{array}{c}\text { Selig and } \\
\text { McGranahan }\end{array}$ & $\begin{array}{c}\text { Spalart- } \\
\text { Allmaras }\end{array}$ & $\begin{array}{c}\text { Realizable } \\
\boldsymbol{k}-\boldsymbol{\varepsilon}\end{array}$ & $\begin{array}{c}\text { Standard } \\
\boldsymbol{k}-\boldsymbol{\omega}\end{array}$ \\
\hline $\mathbf{- 6 . 0 6}$ & 0.012 & 0.020 & 0.018 & 0.017 \\
\hline $\mathbf{- 4 . 0 0}$ & 0.010 & 0.018 & 0.016 & 0.016 \\
\hline $\mathbf{- 1 . 9 6}$ & 0.009 & 0.017 & 0.016 & 0.015 \\
\hline $\mathbf{0 . 0 7}$ & 0.008 & 0.017 & 0.016 & 0.015 \\
\hline $\mathbf{2 . 1 4}$ & 0.008 & 0.018 & 0.017 & 0.016 \\
\hline $\mathbf{4 . 1 7}$ & 0.009 & 0.020 & 0.018 & 0.017 \\
\hline $\mathbf{6 . 1 9}$ & 0.011 & 0.023 & 0.021 & 0.020 \\
\hline $\mathbf{8 . 2 6}$ & 0.016 & 0.028 & 0.025 & 0.023 \\
\hline $\mathbf{1 0 . 2 4}$ & 0.024 & 0.036 & 0.030 & 0.028 \\
\hline $\mathbf{1 2 . 3 6}$ & 0.046 & 0.047 & 0.039 & 0.036 \\
\hline $\mathbf{1 3 . 2 4}$ & 0.068 & 0.053 & 0.043 & 0.040 \\
\hline
\end{tabular}

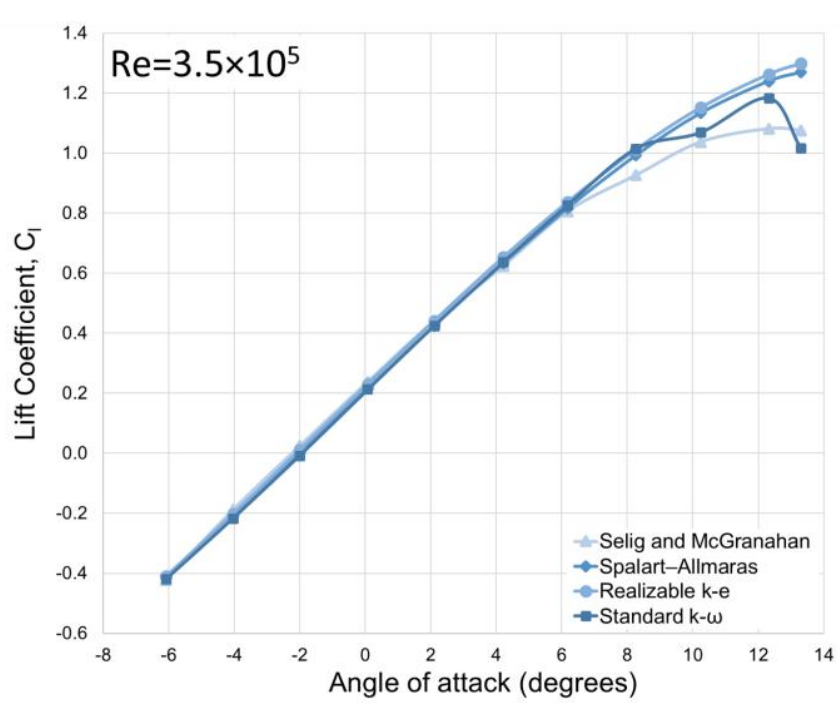

Fig. 4. Comparison between experimental data and computational results of lift coefficient from three turbulence models at $\mathrm{Re}=3.5 \times 10^{5}$

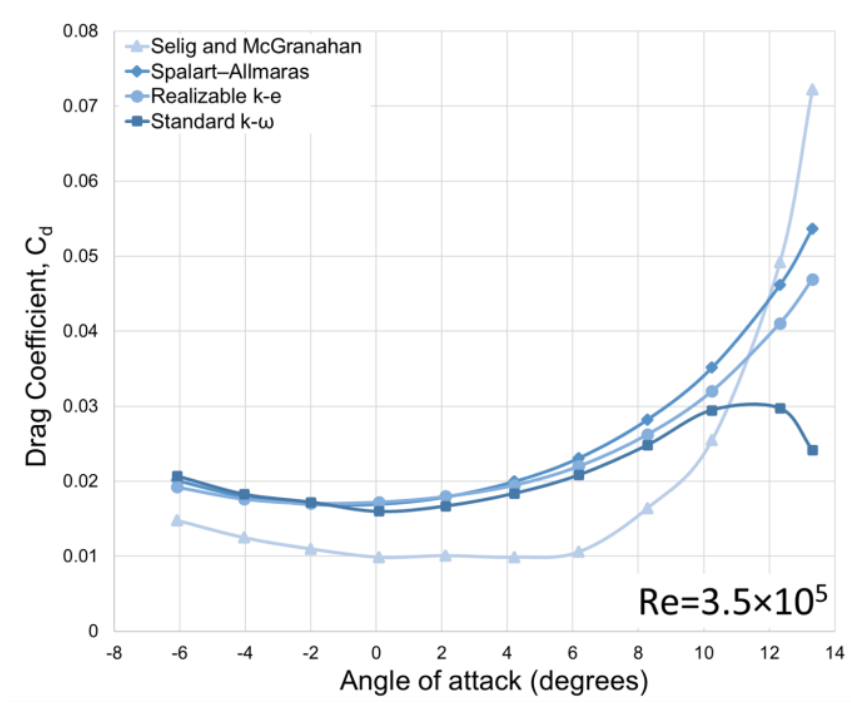

Fig. 5. Comparison between experimental data and computational results of drag coefficient from three turbulence models at $\mathrm{Re}=3.5 \times 10^{5}$

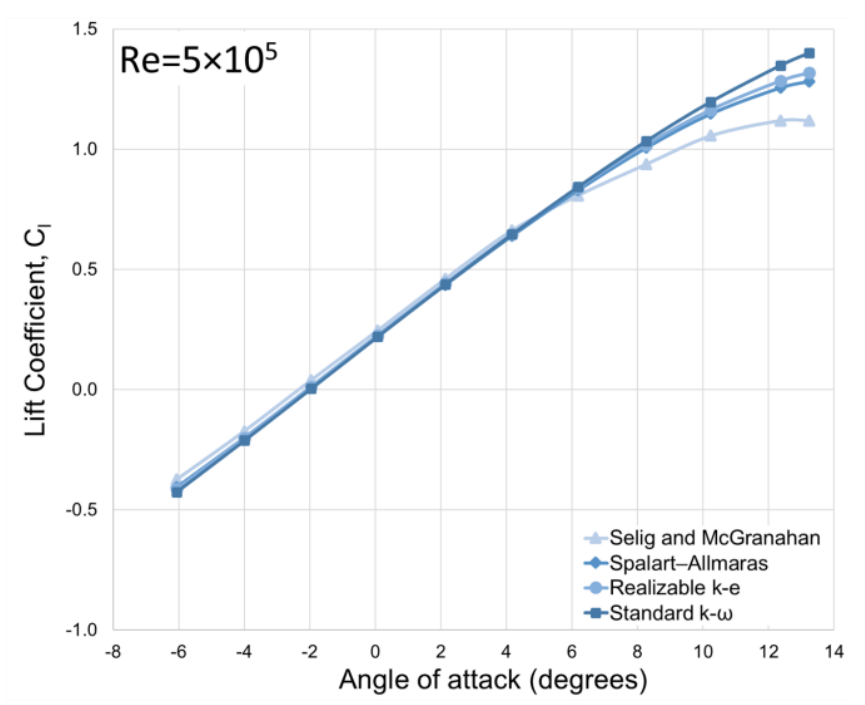

Fig. 6. Comparison between experimental data and computational results of lift coefficient from three turbulence models at $\mathrm{Re}=5 \times 10^{5}$ 


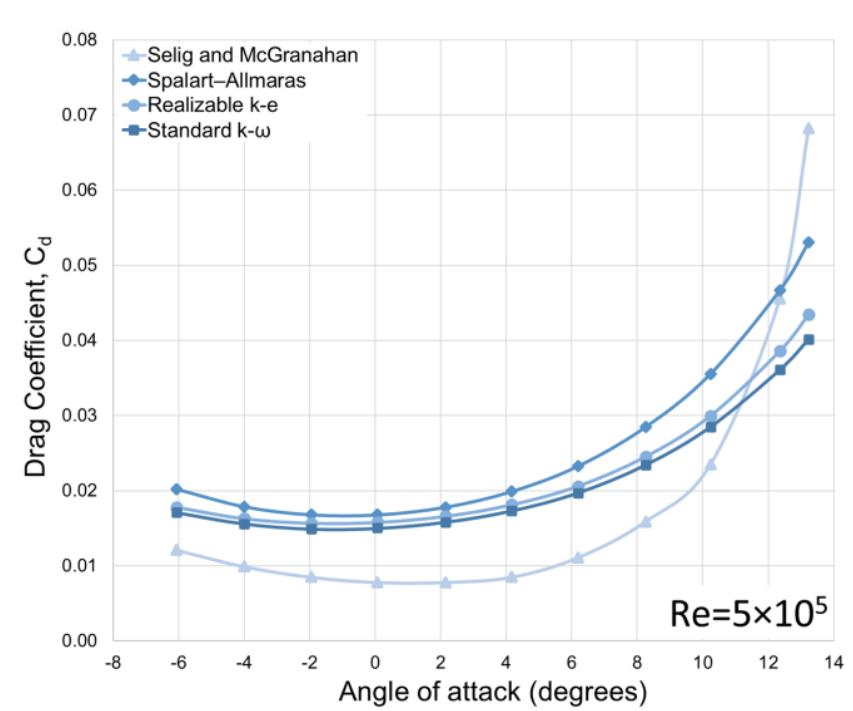

Fig. 7. Comparison between experimental data and computational results of drag coefficient from three turbulence models at $\mathrm{Re}=5 \times 10^{5}$

Fig. 4 shows the lift coefficient at the Reynolds number of $3.5 \times 10^{5}$. It is obvious that the numerical results derived from the three turbulence models that were examined differ slightly, especially for lower angles of attack, in the range from $-6.08^{\circ}$ to $8.27^{\circ}$. Also, for the same range of angles of attack, the lift coefficient increases linearly and the numerical results agree well with the corresponding experimental data. As the angle of attack increases and approaches stall conditions, the relative error between experimental data and computational results also increases. However, in the present study the Standard k- $\omega$ turbulence model agrees with the experimental data at the stall conditions, as shown in Fig. 4.

In Fig. 5 the drag coefficient versus angle of attack for $\mathrm{Re}=3.5 \times 10^{5}$ is presented. The computational results of the drag coefficient are obviously higher than the experimental data, although the curves of the three turbulence models, as well as the experimental data, exhibit the same behavior. At angles of attack near stall conditions, the computational method results in lower values of drag coefficient.

For both coefficients and more importantly for the drag coefficient, the error between experimental data and computational results was expected. Normally, as the flow approaches the airfoil surface, the flow is laminar. The three turbulence models that were examined consider that the boundary layer is turbulent in all region and for that reason the calculated values of drag coefficients are higher than the corresponding experimental data.

The most appropriate model to simulate the flow over S834 airfoil operating at $\mathrm{Re}=3.5 \times 10^{5}$ is the Standard $\mathrm{k}-\omega$ turbulence model. Although the drag coefficient results near the stall angle of attack are worse compared to the other two models, the lift coefficient results are better near stall conditions. Moreover, the smallest relative error of the Standard k- $\omega$ model is $0.98 \%$ at $-6.08^{\circ}$. Near stall, at $12.32^{\circ}$, the relative error is $9.51 \%$ and at $13.31^{\circ}$ the relative error of the lift coefficient is $5.54 \%$ in contrast to the other two models where the relative error near stall is around $20 \%$.

Fig. 6 and Fig. 7 show the results of aerodynamic coefficients at $\operatorname{Re}=5 \times 10^{5}$. The experimental data and simulation results for lift coefficient agree from $-6.06^{\circ}$ to $8.26^{\circ}$ and as the angle of attack approaches the area near stall conditions, a disagreement between the results is observed.

Regarding the drag coefficients for $\mathrm{Re}=5 \times 10^{5}$ (Fig. 7), the computational results are higher than the experimental data, except from the angles of attack near stall, where the experimental data are higher than the computational results.

The most appropriate model for $\operatorname{Re}=5 \times 10^{5}$ is the Spalart-Allmaras turbulence model. This model accurately approaches lift coefficient and is also more accurate near stall compared to the other two models, while it calculates more accurately the drag coefficient near stall. Specifically, the smallest relative error of the Spalart-Allmaras model is $2.68 \%$ at $6.19^{\circ}$. Near stall conditions, at $12.36^{\circ}$, the relative error is $12.23 \%$ and at $13.24^{\circ}$ the relative error of lift coefficient is $14.6 \%$ in contrast to the other two models, where the relative error near stall is $17.7 \%$ for Realizable k- $\varepsilon$ and $25.20 \%$ for Standard $\mathrm{k}-\omega$ turbulence model.

Fig. 8 to Fig. 15 provide the results regarding the static pressure and the velocity magnitude distribution of the flow field over S834 airfoil.

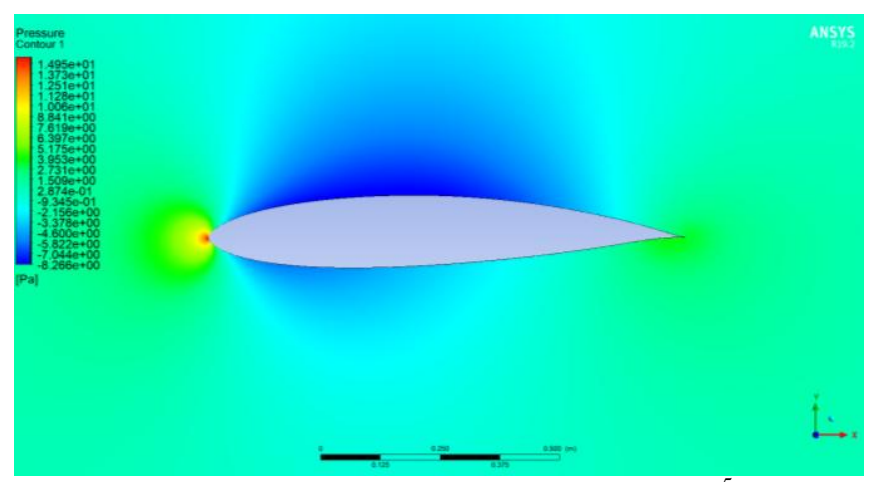

Fig. 8. Contour of static pressure for $\mathrm{Re}=3.5 \times 10^{5}$ at $0.08^{\circ}$ angle of attack and for the Standard k- $\omega$ turbulence model

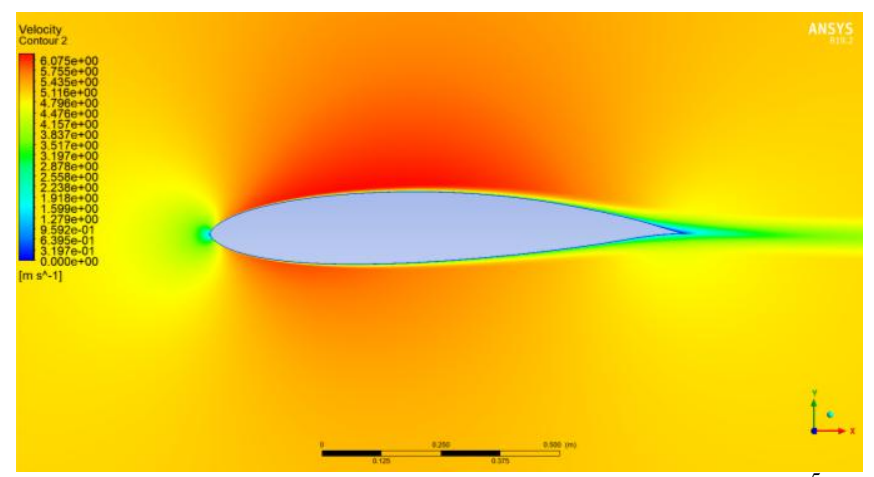

Fig. 9: Contour of velocity magnitude for $\mathrm{Re}=3.5 \times 10^{5}$ at $0.08^{\circ}$ angle of attack and for the Standard k- $\omega$ turbulence model 


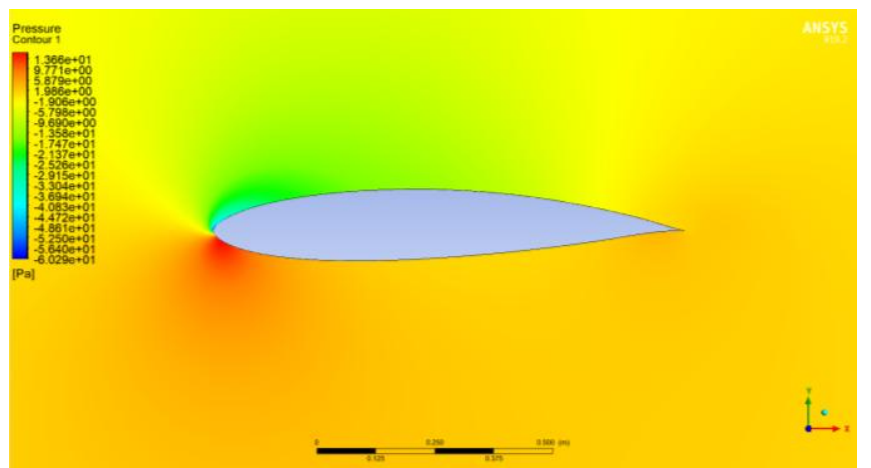

Fig. 10. Contour of static pressure for $\mathrm{Re}=3.5 \times 10^{5}$ at $13.31^{\circ}$ angle of attack and for the Standard k- $\omega$ turbulence model

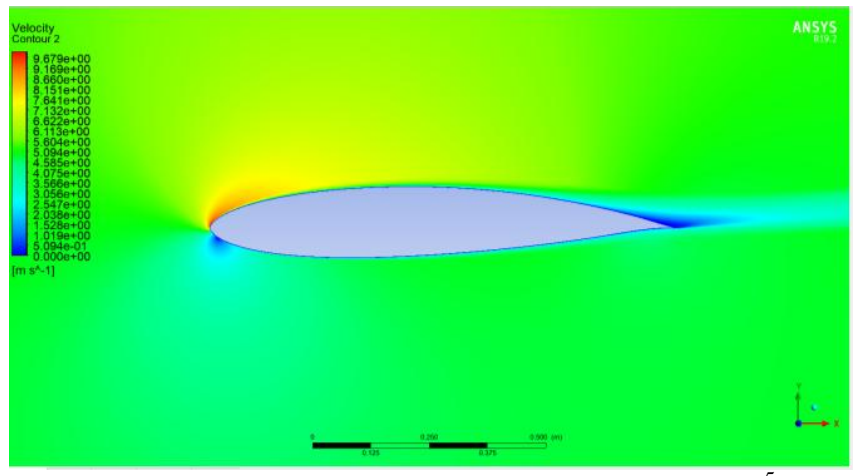

Fig. 11. Contour of velocity magnitude for $\mathrm{Re}=3.5 \times 10^{5}$ at $13.31^{\circ}$ angle of attack and for the Standard k- $\omega$ turbulence model

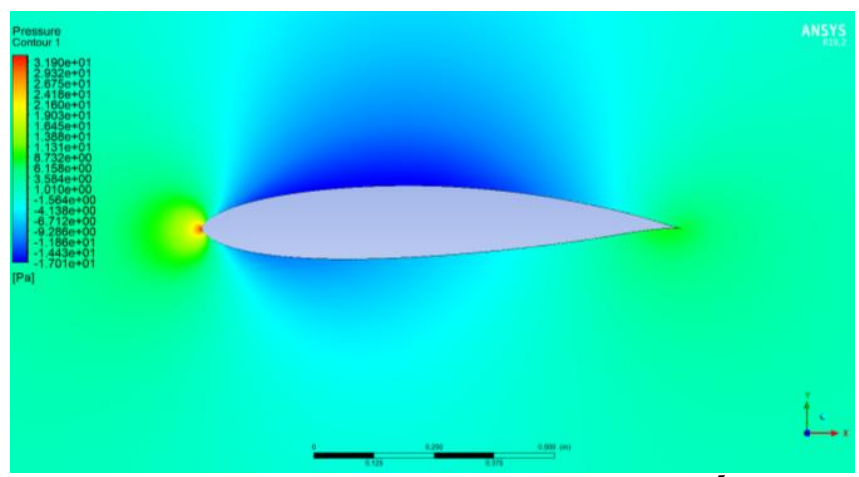

Fig. 12. Contour of static pressure for $\mathrm{Re}=5 \times 10^{5}$ at $0.07^{\circ}$ angle of attack and for the Spalart-Allmaras turbulence model

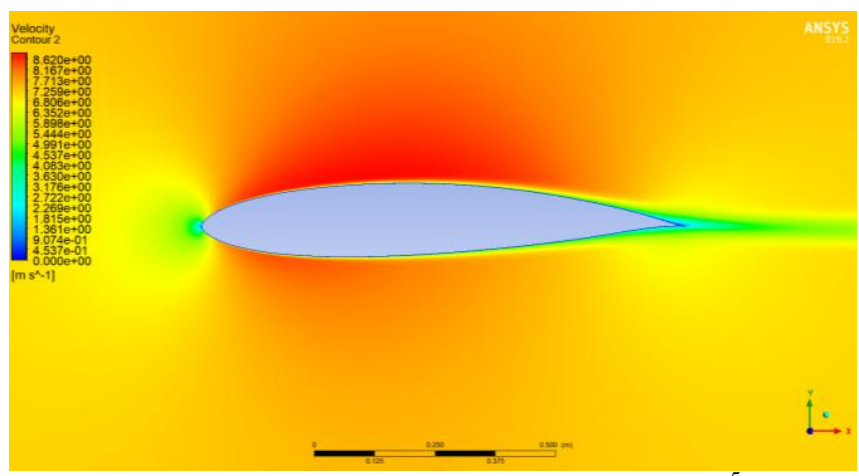

Fig. 13. Contour of velocity magnitude for $\mathrm{Re}=5 \times 10^{5}$ at $0.07^{\circ}$ angle of attack and for the Spalart-Allmaras turbulence model

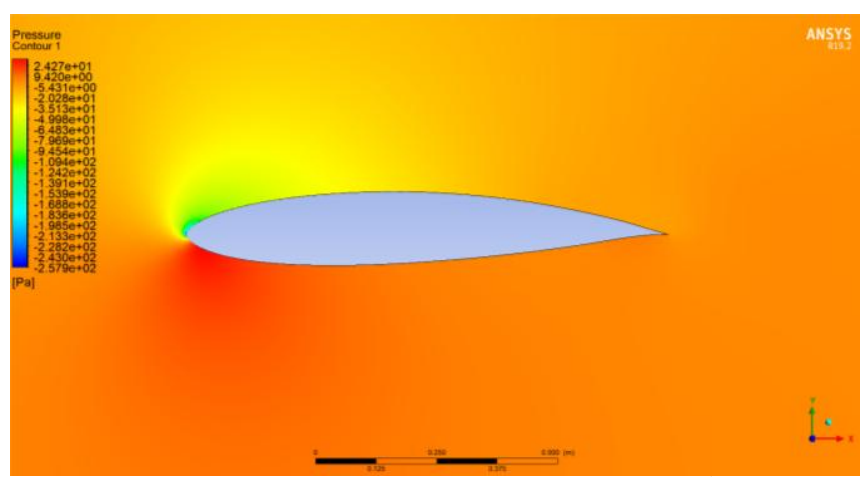

Fig. 14. Contour of static pressure for $\mathrm{Re}=5 \times 10^{5}$ at $13.24^{\circ}$ angle of attack and for the Spalart-Allmaras turbulence model

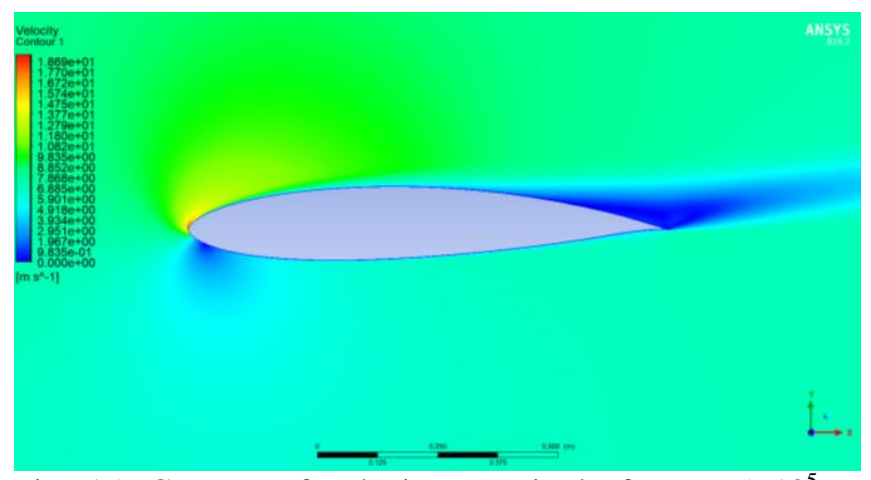

Fig. 15. Contour of velocity magnitude for $\mathrm{Re}=5 \times 10^{5}$ at $13.24^{\circ}$ angle of attack and for the Spalart-Allmaras turbulence model

Since Reynolds number is lower than $5 \times 10^{5}$, which is the critical value of the transition from laminar to turbulent boundary layer over a flat plate, it is possible that laminar separation bubble occurs before the turbulent flow region. It should be noted that the turbulence models that were added in the simulations are not able to predict this phenomenon and capture this separation bubble, as they consider that the flow is turbulent throughout the domain. If the transition region between the laminar flow and the turbulent flow was known, the results would possibly be more accurate.

From the contours of static pressure, it is apparent that the pressure on the lower airfoil surface is greater than the pressure of the free stream, therefore lift force is generated. Finally, from the velocity magnitude contours it was observed that the stagnation point on the front edge of airfoil depends on the angle of attack.

\section{CONCLUSION}

The present study examines the behavior of NREL's S834 airfoil, operating at two different Reynolds numbers. A steady state two-dimensional computational study was held on ANSYS Fluent in order to calculate the aerodynamic coefficients, and more specifically lift and drag coefficients, using three turbulence models. The computational results were compared against experimental data, in order to validate the simulation. The computational results of lift coefficient agreed with the corresponding experimental data in contrast to the drag coefficient, which values were overpredicted. Subsequently, pressure and velocity contours were captured and observed. Although the Reynolds number is less than $5 \times 10^{5}$, the examined turbulence models were not able to 
capture the laminar separation bubble and reattachment phenomenon.

\section{REFERENCES}

[1] E. C. Douvi, A. I. Tsavalos and D. Margaris, "Evaluation of the Turbulence Models for the Simulation of the Flow over a NACA 0012 Airfoil," Journal of Mechanical Engineering Research, vol. 4(3), Mar. 2012, pp. 100-111 Available: https://doi.org/10.5897/JMER11.074.

[2] L. Wang and X. Liu, "Numerical simulation and analysis on aerodynamic performance of wind turbine blade," Taiyangneng Xuebao/Acta Energiae Solaris Sinica, vol. 33(5), 2012, pp. 711-716.

[3] M. Ibrahim, S. Vinci, O. Kartuzova and R. Volino, "CFD simulations of unsteady wakes on a highly loaded low pressure turbine airfoil (L1A)," Proceedings of the ASME Turbo Expo 2012: Turbine Technical Conference and Exposition. Volume 4: Heat Transfer, Parts $A$ and B, 11-15 Jun. 2012, Copenhagen, Denmark, pp. 843-856 Available: https://doi.org/10.1115/GT2012-69770.

[4] H. Shah, S. Mathew and C. Lim, "A novel low reynolds number airfoil design for small horizontal axis wind turbines," Wind Engineering, vol 38(4), Aug. 2014, pp. 377-392 Available: https://doi.org/10.1260/0309-524X.38.4.377.

[5] H. Shah, S. Mathew and C. Lim, "Numerical simulation of flow over an airfoil for small wind turbines using the $\gamma$-Re $\theta$ model," International Journal of Energy and Environmental Engineering, vol. 6(4), Oct. 2015, pp. 419-429 Available: https://doi.org/10.1007/s40095-015-0188-7.

[6] U. Chaudhary and S. Nayak, "Micro and small-scale HAWT blades airfoils study through CFD for low wind applications (2016)," $12^{\text {th }}$ IEEE International Conference Electronics, Energy, Environment, Communication, Computer, Control: (E3-C3) (2015 Annual IEEE India Conference (INDICON)), 17-20 Dec. 2015, New Delhi, India Available: https://doi.org/10.1109/INDICON.2015.7443703.

[7] S. Mauro, R. Lanzafame, M. Messina and D. Pirrello, "Transition turbulence model calibration for wind turbine airfoil characterization through the use of a Micro-Genetic Algorithm," International Journal of Energy and Environmental Engineering, vol. 8(4), Oct. 2017, pp. 359-374 Available: https://doi.org/10.1007/s40095-017-0248-2.

[8] Z. Belfkira, H. Mounir and A. El Marjani, "Comparison of experimental and numerical performances of a wind turbine airfoil using XFOIL and computational fluid dynamics simulation," International Review on Modelling and Simulations, vol. 12(4), 2019 pp. 212-221 Available: https://doi.org/10.15866/iremos.v12i4.16175.

[9] S. Khan, M. Bashir, M. Baig and F. Ali, "Comparing the effect of different turbulence models on the CFD predictions of NACA0018 airfoil aerodynamics," CFD Letters, vol. 12(3), Mar. 2020, pp. 1-10 Available: https://doi.org/10.37934/cfdl.12.3.110

[10] ANSYS® (2019, March 20). Academic Research (Release 19.0) [Online]. Available: http://www.ansys.com.

[11] L. Tangier and D. M. Somers, NREL Airfoils Families for HAWTs, Technical Report, NREL/TP-442-7109, National Renewable Energy Laboratory, Golden, CO, USA, 1995 Available: https://doi.org/10.2172/10106095.

[12] D.M. Somers, S833, S834, and S835 Airfoils, Technical Report, NREL/SR-500-36340, National Renewable Energy Laboratory, Golden, CO, USA, 2005 Available: https://doi.org/10.2172/15020040.

[13] NREL's S834 Airfoil (s834-nr) Available: $\frac{\mathrm{http}: / / \text { airfoiltools.com/airfoil/details?airfoil=s834-nr. }}{\text { S834 Airfoil }}$ Shape $\quad$ Available:

[14] S834 Airfoil Shape https://wind.nrel.gov/airfoils/shapes/S834 Shape.html.

[15] M. Selig, B. McGranahan, "Wind Tunnel Aerodynamic Tests of Six Airfoils for Use on Small Wind Turbines," Journal of Solar Energy Engineering, vol. 126(4), Nov. 2004, pp. 986-1001, Available: https://doi.org/10.1115/1.1793208.

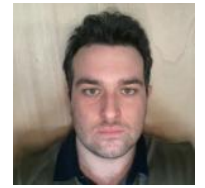

Spyridon D. Skaltsogiannis, Born in Zakynthos island, Greece on September 28th, 1998. He is an undergraduate student in the division of Energy, Aeronautics \& Environment in Mechanical Engineering and Aeronautics Department at University of Patras. His interests are renewable energy sources, wind energy, computational fluid dynamics and net zero energy buildings. In his diploma thesis was dealing with aerodynamic analysis of small wind turbine rotor.

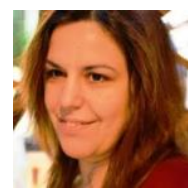

Eleni C. Douvi, born in Korinthos, Greece on March $15^{\text {th }}, 1984$. She is post-doctoral researcher of Mechanical Engineering and Aeronautics Department at University of Patras. Her research activity as post-doctoral researcher is CFD analysis of innovative solar collector with integration of Phase Change Materials, as well as the proposal of the optimum geometry of a horizontal axis tidal turbine rotor. Her doctoral thesis was experimental and computational investigation of aerodynamic behavior of wings in heavy rain, applied to horizontal axis wind turbine blades. In her diploma thesis was dealing with the experimental study of fluid mechanics applying LDA and PDA measurements. Her research activities/fields are wind and solar energy systems, tidal turbines, multiphase flows, computational and experimental fluid dynamics, aerodynamics, hydrodynamics, phase change materials, heat transfer and development of computational codes. She is participating in 14 international conferences on the above scientific areas and has 10 publications on high-interested impact factor Journals. She has been awarded an Heracleitus II PhD Fellowship for her doctoral thesis and a scholarship from Greek State Scholarships Foundation (IKY) for postdoctoral research in Greece. Dr. Eleni Douvi is participating in several research projects funding by General Secretariat for Research and Technology and BIG SOLAR S.A. Also she is member of TCG (Technical Chamber of Greece).

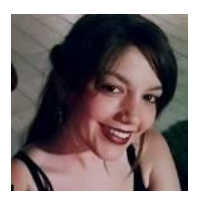

Dimitra C. Douvi, born in Korinthos, Greece on May $31^{\text {st }}$, 1989. She has Ph.D. in Mechanical Engineering and Aeronautics Department and B.Sc. in Mathematics Department of the University of Patras. Her doctoral thesis is experimental and computational investigation of aerodynamic behavior of wind turbine rotor in multiphase flows. Her research activities/fields are multiphase flows, wind energy systems, computational fluid dynamics, aerodynamics, development of computational codes. She is participating in 7 international conferences on the above scientific areas and has 4 publications on high-interested impact factor Journals. Dr. Dimitra Douvi is participating in 2 research projects supported by BIG SOLAR S.A. in Greece.

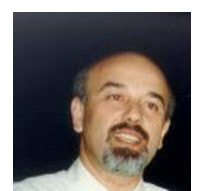

Dionissios P. Margaris, born in Zakynthos island, Greece on September $28^{\text {th }}, 1953$. He is Professor in Mechanical Engineering and Aeronautics Department at the University of Patras, Patras, Greece. His research activities/fields are multiphase flows of gas-liquid-solid particles, gas-liquid two-phase flow air-lift pump performance, centrifugal and $\mathrm{T}$-junction separation modeling in gas-liquid two-phase flow, experimental and theoretical investigation of hot air dehydration of agricultural products, experimental and theoretical investigation of capillary pumped loops, steady and transient flows in pipes and network and numerical simulation of centrifugal pump performance. Also, he is dealing with fluid dynamics analysis of wind turbines and aerodynamic installations, aero-acoustic analysis and environmental impacts of wind turbines. He is participating in over 150 international conferences on the above scientific areas and has over 90 publications on high-interested impact factor Journals. Prof. Dionissios P. Margaris is participating in several research projects supported by HAI, GSRT, CEC-THERMIE. Also he is member of AIAA, AHS, ASME and EUROMECH unions as well as of TCG (Technical Chamber of Greece) 